\title{
Prática pedagógica de professoras alfabetizadoras iniciantes: processos de produção e contribuições para a formação
}

\author{
Simone Regina Manosso Cartaxoid \\ Universidade Estadual de Ponta Grossa, Ponta Grossa, PR, Brasil \\ Josemary Scosiii(i) \\ Universidade Estadual de Ponta Grossa, Ponta Grossa, PR, Brasil
}

\begin{abstract}
Resumo
Neste artigo, analisa-se o processo de produção da prática pedagógica das professoras alfabetizadoras iniciantes, a fim de contribuir para a sua formação. $O$ referencial teórico está fundamentado na compreensão da teoria como expressão da prática (MARTINS, 1996). A pesquisa é qualitativa e a análise fundamentou-se em Bardin (2011). Os dados foram obtidos por meio de questionários aplicados em 40 escolas de uma Rede Municipal de Ensino e de entrevistas semiestruturadas com 17 professoras. Os resultados indicam que a prática pedagógica das docentes se constitui por desafios, por determinantes externos e internos e por estratégias produzidas a partir dos problemas originados na prática. O processo formativo dessas professoras requer ampliação dos espaços coletivos de trabalho e compreensão da especificidade da alfabetização.
\end{abstract}

Palavras-chave

Professora alfabetizadora. Formação docente. Desenvolvimento profissional.

\section{Pedagogical practice of beginning literacy teachers: production processes and contributions to training}

\begin{abstract}
In this paper, the production process of the pedagogical practice of the beginning literacy teachers is analyzed, in order to contribute to their training. The theoretical framework is based on the understanding of theory as an expression of practice (MARTINS, 1996). The research is qualitative and the analysis was based on Bardin (2011). The data were obtained through questionnaires applied in 40 schools in a Municipal Education Network and semi-structured interviews with 17 teachers. The results indicate that the teachers' pedagogical practice is constituted by challenges, by external and internal determinants and strategies produced from the problems originated in practice. The training process of these teachers requires an expansion of collective work spaces and an understanding of the specificity of literacy.
\end{abstract}

\section{Keywords}

Literacy teacher. Teacher education. Professional development. 


\title{
Práctica pedagógica de profesoras principiantes de alfabetización: procesos de producción y contribuciones a la formación
}

\begin{abstract}
Resumen
En este artículo se analiza el proceso de producción de la práctica pedagógica de las profesoras principiantes de alfabetización para contribuir a su formación. El marco teórico se basa en la comprensión de la teoría como expresión de la práctica (MARTINS, 1996). La investigación es cualitativa y el análisis se basó en Bardin (2011). Los datos se obtuvieron por medio de cuestionarios aplicados en 40 escuelas en una Red Municipal de Educación y entrevistas semiestructuradas con 17 profesoras. Los resultados indican que la práctica pedagógica de las docentes está constituida por desafíos, por determinantes externos e internos y por estrategias producidas a partir de los problemas originados en la práctica. El proceso de capacitación de estas profesoras requiere ampliación de los espacios de trabajo colectivos y comprensión de la especificidad de la alfabetización.
\end{abstract}

\section{Palabras clave}

Profesora de alfabetización. Formación docente. Desarrollo profesional.

\section{Introdução}

Neste texto, analisamos o processo de produção da prática pedagógica das professoras alfabetizadoras iniciantes, considerando que os primeiros anos de iniciação da carreira são em torno de dois a três anos, como afirma Huberman (1995). Esse período, também conhecido como inserção profissional do professor, é marcado pelo choque de realidade sobre a sua nova condição, que passa de aprendiz para a atuação da prática pedagógica. Huberman (1995) destaca que, no início, a carreira docente pode pontuar elementos significativos para o profissional, pois o professor encontra-se motivado por fazer parte de um grupo que pertence a uma classe profissional; é uma fase de descobertas que "[...] traduz o entusiasmo inicial, a experimentação, a exaltação por estar, finalmente, em situação de responsabilidade (ter a sua sala de aula, os seus alunos, o seu programa)" (HUBERMAN, 1995, p. 39).

Diante do exposto, entendemos, fundamentadas em estudos sobre inserção profissional docente (HOÇA; ROMANOWSKI; CARTAXO, 2016; MIRA et al., 2014; MIRA; ROMANOWSKI, 2016), que, na complexidade do espaço escolar, o período marcado pelo choque de realidade necessita de um acompanhamento para amenizar as situações de insegurança, a sensação de isolamento, a ansiedade e os medos.

Educ. Form., Fortaleza, v. 6, n. 2, e3434, maio/ago. 2021

DOI: https://doi.org/10.25053/redufor.v6i2.3434

https://revistas.uece.br/index.php/redufor/index 
Soma-se a esse contexto da inserção profissional o fato de que muitas professoras iniciantes assumem a função como alfabetizadoras nas escolas públicas, aumentando os desafios que constituem esse período. Os desafios para a professora iniciante alfabetizadora caracterizam-se pela necessidade de conhecimentos, além dos relativos ao ensino, àqueles específicos da alfabetização, ou seja, as diferentes facetas da alfabetização, em especial as relacionadas à escrita, a saber: a faceta linguística "[...] representação visual da cadeia sonora da fala"; a faceta interativa da língua - "[...] a escrita como veículo de interação entre outras pessoas, de expressão e compreensão de mensagens"; e a faceta sociocultural - uso da escrita em contextos socioculturais (SOARES, 2016, p. 28-29).

A especificidade da alfabetização ocupa espaço relevante nas políticas educacionais com justificativas fundamentadas nos índices de analfabetismo que persistem no Brasil e nos baixos índices apontados nas avaliações em larga escala (FRADE, 2019; MORTATTI, 2019). No entanto, no campo das políticas sobre a formação de professores, justificativas reducionistas com foco no fracasso/sucesso são insuficientes para compreender o contexto das práticas alfabetizadoras.

Ao elegermos a prática alfabetizadora, partimos da compreensão de que ela é produzida intencionalmente em um contexto situado no tempo e no espaço e, por isso, recebe interferências externas e internas. Nesse sentido, essa prática é compreendida na dimensão de uma prática social, a qual abrange de modo mais amplo processos formativos que englobam aspectos políticos, culturais, sociais e históricos.

Em levantamento realizado no Banco Digital de Teses e Dissertações (BDTD) sobre a prática do professor alfabetizador, foram localizadas 39 pesquisas. A busca foi realizada em 2018 e compreendeu o período de 1994 a 2018, considerando como palavras-chave de busca as que seguem: "prática do professor iniciante", "prática do professor alfabetizador", "prática pedagógica do professor alfabetizador", "prática do alfabetizador", "prática da professora alfabetizadora", "prática pedagógica do alfabetizador", "prática pedagógica da professora alfabetizadora", "prática pedagógica do professor alfabetizador iniciante". Dentre as 39 pesquisas, não foi localizada nenhuma com a especificidade da prática da professora alfabetizadora iniciante. Essa lacuna nas pesquisas reforça nossa intenção investigativa, que questiona: "Como ocorre o processo de produção da prática pedagógica de professoras alfabetizadoras iniciantes?", e tem 
como objetivo a análise do processo de produção da prática pedagógica das professoras alfabetizadoras iniciantes, a fim de identificar possíveis contribuições para o seu processo formativo.

Os fundamentos que orientam a análise do processo de produção da prática pedagógica das professoras alfabetizadoras iniciantes ancoram-se no eixo epistemológico da teoria como expressão da prática fundamentada em Martins (1996, p. 84), que explicita: "A prática já não é mais guiada pela teoria, mas a teoria vai expressar a ação prática dos sujeitos". Nesse sentido, o fazer passa a ser visto como algo essencial no contexto educativo. Os professores não são mais reconhecidos apenas como executores de tarefas, mas sim como sujeitos críticos que produzem conhecimentos por meio de práticas contextualizadas. Os professores, portanto, como agentes de sua prática, refletem criticamente e recriam novos caminhos para a atuação educativa.

Articulados ao conceito de teoria como expressão da prática, tomamos de Santos (1992) os conceitos de produção e de distribuição do conhecimento, os quais não se sustentam na hierarquização, em outras palavras, na transmissão e na assimilação do conhecimento, mas sim em uma teoria em que todos são produtores e distribuem conhecimentos, por meio das suas experiências e pelo movimento da prática que realizam com a intenção de resolver problemas e conflitos. Para o autor, a ação prática é um determinante que consiste em alterar as formas de agir e de pensar do sujeito, seja em contexto escolar social ou na prática da mais-valia.

O texto, a partir desta Introdução, constitui-se pela apresentação da metodologia, a discussão do processo de produção da prática alfabetizadora, destacando os desafios, os determinantes contextuais, as estratégias das professoras e a reflexão sobre a prática. Decorrente dessa categorização, discutimos a reflexão das professoras sobre sua prática, finalizando com apontamentos sobre possíveis contribuições para 0 processo formativo das professoras alfabetizadoras iniciantes.

\section{Metodologia}

A pesquisa foi desenvolvida em uma perspectiva qualitativa com análise de conteúdo (BARDIN, 2011). Os dados foram obtidos por meio de questionários e de entrevistas semiestruturadas que possibilitaram a descrição e o exame das práticas 
pedagógicas das professoras alfabetizadoras iniciantes com vistas a evidenciar como são produzidas.

Os questionários, contemplando 16 questões (com perguntas fechadas e abertas), buscaram traçar o perfil das professoras, a experiência profissional, os desafios e a descrição da prática alfabetizadora. Os questionários foram aplicados em 40 escolas de uma Rede Municipal de Ensino (RME), com resposta de 66 professores.

$\mathrm{Na}$ sequência, foram realizadas as entrevistas com 17 professoras alfabetizadoras iniciantes, em 10 escolas. O critério para a escolha das entrevistadas considerou que a professora deveria estar atuando no primeiro ano do Ensino Fundamental e ser iniciante na função, considerando Huberman (1995). Dessa forma, as participantes tinham até três anos de experiência e atuavam com $01^{\circ}$ ano. As entrevistas contemplaram questões relativas ao desenvolvimento profissional da professora alfabetizadora, ao planejamento e organização da prática, ao processo de formação inicial e às iniciativas para resolver os problemas da prática.

Com o intuito de preservar a identidade das participantes, elas serão identificadas por códigos contendo letras e números, como, por exemplo, P2Q e P8E. A letra "P" refere-se à palavra "Professora"; a letra "Q", a "Questionário"; e a letra "E", à "Entrevista". Os números correspondem a cada professora participante. $O$ projeto de pesquisa foi submetido à Plataforma Brasil, sob o número 65 087517.5.0000.5694, e teve o Parecer de aprovação número 2.083.564. As participantes foram informadas sobre os trâmites da pesquisa e assinaram o Termo de Consentimento Livre e Esclarecido.

As categorias que emergiram da análise e possibilitaram apontar contribuições para 0 processo formativo das professoras alfabetizadoras iniciantes, neste estudo, foram: a) desafios da prática alfabetizadora; b) determinantes da prática pedagógica alfabetizadora; c) estratégias produzidas a partir dos problemas originados na prática; d) reflexão sobre a prática.

\section{Caracterização do processo de produção da prática alfabetizadora: desafios, determinantes, estratégias e reflexões}

No contexto da prática da professora alfabetizadora iniciante, emergiram desafios, determinantes contextuais externos e internos e estratégias produzidas pelas professoras 
no próprio contexto da prática. Na perspectiva teórica que assumimos, a teoria como expressão da prática, somos instigadas a encontrar categorias que caracterizam e contextualizam a prática, a fim de formular proposições para superar os desafios postos pela própria prática. Assim sendo, apresentamos nossas análises a seguir.

\subsection{Desafios da prática alfabetizadora}

Ensinar é um ato complexo, pois demanda um número significativo de ações, exigindo do professor muito além do conhecimento específico do conteúdo que irá desenvolver, pois "[...] o ensino estabelece conexões com os fatores contextuais ao refletir sobre os valores mais amplos da sociedade em que vivem os alunos, mas também aqueles que são mais próximos e localizados" (VEIGA, 2011, p. 31).

O contexto da prática, neste estudo, foi identificado com inúmeros desafios que se referem à especificidade da prática alfabetizadora e aos desafios mais amplos relacionados ao contexto escolar no qual a criança está inserida. Os desafios relativos à alfabetização referem-se à escolha de métodos, adequar as práticas, como realizar um planejamento que atinja todas as crianças, organizar rotinas de leituras e de atividades. Nos relatos das professoras, encontramos: "[...] inseguranças em relação ao domínio/escolha do método alfabetizador mais adequado ao perfil da turma" (P2Q); "[...] buscar um método que facilite o aprender do aluno" (P8Q); "[...] encontrar formas diversificadas para planejar" (P11Q).

O desafio da escolha do método indica uma necessidade de articular a teoria que sustenta o processo e a prática alfabetizadora. Nesse sentido, o alerta de Mortatti (2006) indica que não se pode pensar que um método isoladamente possa resolver o problema da alfabetização. As disputas históricas sobre os métodos de alfabetização marcaram um período na história da alfabetização no Brasil (CARTAXO; FONTANA; SMANIOTTO; 2020; CARTAXO; ROMANOWSKI; MARTINS, 2016; HOÇA; ROMANOWSKI; CARTAXO, 2016). Além disso, compreensões equivocadas, na década de 1980, levaram a um processo de "desmetodização" da alfabetização (SOARES, 2004). A disputa sobre os métodos de alfabetização ainda persiste e está intimamente ligada à concepção de alfabetização e às políticas nacionais, conforme críticas delineadas por Frade (2019) e Mortatti (2019). 
O planejamento é outro desafio para as alfabetizadoras. Elas relataram que, para construir o planejamento, procuram socializar com as outras professoras as suas dúvidas, suas incertezas e suas dificuldades, e é nesse momento que "[...] os novos docentes interiorizam as normas, valores e condutas que caracterizam a cultura escolar na qual se integram" (VAILLANT; MARCELO, 2012, p. 132). Nessa perspectiva, evidenciamos como as professoras buscavam resolver esses desafios:

[...] aqui na escola, como é integral, na sexta-feira à tarde, nós temos um horário só para planejar; então, eu me sento com as outras professoras do $1^{\circ}$ ano e planejamos em conjunto, fazemos uma troca do que faremos na semana. (P2E).

[...] eu tenho uma colega que me ajuda; planejamos juntas. (P13E).

[...] uso sugestões de ideias de outras professoras. (P5E).

[...] eu utilizo bastante conversas com as professoras da escola. (P8E).

O impacto da realidade enfrentada pelas professoras iniciantes acaba repercutindo nos desafios de adequar planejamentos, pois os alunos aprendem de formas diferentes e as salas de aula são constituídas por vários níveis de aprendizagem. Sobre esse aspecto, identificamos que as professoras alfabetizadoras justificam que é necessária a realização de atividades diversificadas para os discentes, já que atuam em classes heterogêneas.

O professor alfabetizador tem uma responsabilidade muito grande e deve ter consciência disso; ele precisa investigar seu aluno e procurar meios que efetivem de fato seu aprendizado. (P16E).

[...] gosto de construir com os alunos e mostrar a eles que são autores do processo na elaboração de um texto, por exemplo. (P9E).

[...] procuro trabalhar atividades diferenciadas; às vezes, jogos; outras vezes, atividades no livro, no quadro (P2E).

As docentes também destacam que o pouco tempo em sala de aula é um complicador para elaborar tais atividades e solicitam mais horas de planejamentos para a elaboração de atividades que supram as necessidades dos educandos. As professoras alfabetizadoras revelam a preocupação em levar o novo para a sala de aula, a importância de sensibilizar os estudantes e a necessidade do diálogo e da construção coletiva.

No que diz respeito aos desafios do contexto escolar, as professoras relatam alguns fatores relacionados aos processos de ensino e de aprendizagem, como a 
participação e o interesse da família, a realidade social do aluno, a desmotivação, a indisciplina e a falta de apoio. Os excertos que se subtraem dos instrumentos de coleta de dados demonstram as aflições e os desafios das profissionais:

\author{
[...] dificuldade de enfrentar a realidade social do aluno. (P5Q). \\ [...] falta de interesse da família; alunos desmotivados. (P6Q). \\ [...] falta de apoio da equipe pedagógica e conciliar o planejamento para os \\ alunos com mais e menos dificuldades. (P7Q).
}

[...] enfrentar a realidade do aluno. (P9Q).

As professoras pontuam a fragilidade no apoio pedagógico e que, muitas vezes, também não sabem como lidar com os desafios, culminando em falta de auxílio a elas. Nesse sentido, consideramos que as colaborações da equipe pedagógica, da direção e da família nos processos de ensino e de aprendizagem constituem formas importantes para a prática pedagógica das professoras alfabetizadoras iniciantes.

\title{
3.2 Determinantes da prática pedagógica alfabetizadora
}

A prática pedagógica alfabetizadora, compreendida na dimensão de uma prática social, está relacionada a determinantes internos (rotina, calendário letivo, projeto Pedagógico, por exemplo) e externos (como as Diretrizes Curriculares do Município, a Base Nacional Curricular Comum, as avaliações em larga escala e a formação continuada).

Esse contexto de determinação parece afetar as professoras, que dizem se sentir engessadas e incomodadas pelo sistema e pelas políticas. São determinações que, por vezes, atingem a autonomia da escola e das docentes, como no caso das avaliações em larga escala, que exigem trabalhar alguns conteúdos específicos cobrados nas provas. As professoras comentam: "[...] nós temos um conteúdo programático para seguir. Para trabalhar no semestre, precisamos seguir o que é solicitado" (P9Q); "[...] agora houve uma solicitação que precisamos trabalhar só o fonológico nas atividades" (P4E).

Contudo, as professoras destacam que as formações oferecidas pela Secretaria Municipal de Educação (SME) também são determinantes da prática. O Programa Nacional de Alfabetização na Idade Certa (Pnaic), desenvolvido em todo o Brasil, por 
exemplo, foi considerado pelas participantes da pesquisa como fundamental para contribuir com sua prática em sala de aula:

[...] não tive uma base efetivamente boa para trabalhar com alfabetização, mas o que aprendi foi correndo atrás, partilhando experiências com colegas de escola e também do Pnaic. (P16Q).

[...] vou começar a fazer o pacto; as professoras do $1^{\circ}$ ano fazem e ajuda bastante nas atividades, nos planejamentos e nas dificuldades. (P11E).

É um determinante externo que influência no planejamento e na troca de experiências, pois possibilita às professoras conhecer o trabalho das colegas, formar-se e ampliar suas reflexões sobre o processo de alfabetização.

Além dos determinantes já apontados, identificamos que a função de professora alfabetizadora decorre de opções pessoais determinadas pelo contexto em que vivem. Algumas profissionais relataram que optaram pela alfabetização em busca da constituição de uma carreira como alfabetizadora, pois tinham interesse na alfabetização, como também em enfrentar os seus determinantes internos, entre eles 0 medo, descobrirem se possuíam perfil para atuar, se gostavam do processo de alfabetização: "[...] interesse pela alfabetização" (P6Q); "Me propus a assumir uma das turmas de alfabetização, se fosse possível, para enfrentar o medo. Desafio de terminar o ano e terminá-lo com um 1ํano" (P1Q1).

Outras professoras destacam que assumiram as classes de alfabetização porque tinham que suprir uma necessidade da escola, ou porque era a única turma disponível no momento que haviam se apresentado para assumir seu cargo, ou ainda por indicação da sua superior:

[...] a turma foi escolhida pela equipe pedagógica conforme a necessidade da escola. (P2Q).

[...] iniciei na instituição por meio do concurso público, desta forma assumi a turma que estava com outra professora temporária. (P8Q).

[...] a equipe de gestão que optou. (P16Q).

[...] decidido pela coordenação. (P10E).

Como podemos observar, classes de alfabetização são destinadas às professoras iniciantes atendendo a uma demanda da escola, mesmo sabendo que a fase 
da alfabetização é um processo desafiador e o professor iniciante precisa lidar com muitos desafios ao ingressar na carreira docente.

\subsection{Estratégias produzidas a partir dos problemas originados na prática}

No início da inserção profissional, as professoras buscam formas de organizar a prática pedagógica e superar os desafios postos pela prática. Ao perguntarmos às professoras sobre as estratégias que usavam, elas indicaram que procuram fazer movimentos de trocas com outras docentes:

[...] uso sugestões de ideias de outras professoras. (P5E).

[...] eu utilizo bastante conversas com as professoras da escola. (P8E).

[...] troco bastante experiência; é uma coisa muito rica: trocar figurinhas com outras professoras. (P9E).

[...] eu sempre estou trocando ideias. Eu acho enriquecedor trocar as experiências com quem está passando pela mesma situação. (P14E).

[...] eu tenho uma colega que me ajuda. Planejamos juntas. (P13E).

A interação com o coletivo, de alguma forma, contribui para a professora criar estratégias para a sua atuação alfabetizadora. Ao abrir-se ao novo, ela consegue realizar reflexões que confrontam situações anteriores e, aos poucos, vão the proporcionando o aperfeiçoamento profissional e consequentemente a segurança na sua prática pedagógica.

Outra estratégia na prática das docentes diz respeito ao uso da internet. As 17 professoras citaram que utilizam com frequência a internet na busca de ideias para atividades diferentes. Elas acessam blogs, sites educacionais e revistas on-line, que auxiliam na sua prática pedagógica no sentido de suprir as suas necessidades como alfabetizadoras. Segundo as professoras, o acesso à internet também possibilita a visualização e a discussão entre as colegas sobre notícias, sejam de economia, política ou mesmo educação. Elas destacam que: "[...] agora podemos dizer que as mídias estão em toda parte. A internet está aí para mostrar práticas diferentes de outros professores [...]. Eu uso relatos das redes sociais" (P8E); "[...] uso a internet para fazer cursos a distância também" (P9Q). 
Embora as professoras se utilizem de estratégias de pesquisa em suportes e ferramentas tecnológicas para organizar o seu trabalho, na rotina da sua sala de aula elas não as utilizam com seus alunos. Isso indica a necessidade:

[...] de um maior investimento na formação e capacitação dos formadores no e para o uso pedagógico das TIC por se acreditar que a (falta) de formação/ conhecimentos na área e as concepções e atitudes que detêm (sobre o ensino, as potencialidades das TIC, etc.) atuam como barreiras à preparação profissional [...]. [Além disso,] [...] tendem a influenciar não apenas as práticas, mas também o pensamento dos profissionais [...]. (FONSECA, 2019, p. 21, grifos da autora).

\subsection{Reflexão sobre a prática}

Olhamos para o contexto de produção das práticas alfabetizadoras considerando que as professoras são sujeitos críticos que produzem conhecimentos por meio de práticas contextualizadas. Desse modo, como agentes de sua prática, elas refletem criticamente e recriam novos caminhos para a atuação educativa.

Apreendemos dos relatos das professoras alfabetizadoras o que elas pensam sobre a prática pedagógica que realizam. Elas refletem sobre o processo de aprendizado do aluno e sabem da importância de uma prática que vá ao encontro das necessidades deles, concomitantemente aos desafios de superar suas próprias indagações de assumirem-se professoras, como seres que transformam as condições do aprender. Como afirma Freire (1996, p. 23), "[...] uma das tarefas mais importantes da prática educativo-crítica é propiciar as condições em que os educandos em relação uns com os outros e todos com o professor ou a professora ensaiam a experiência profunda de assumir-se". Para o autor, é necessário que os sujeitos se assumam como seres sociais e históricos, pois são indivíduos pensantes, comunicantes e capazes de transformar e criar realidades diferentes para si.

Prepondera, nos relatos, a relação com o processo de aprendizagem que exigem da professora que atue em um meio complexo, em um cenário vivo e mutável com muitos fatores e situações de aprendizagem que requerem uma forma singular de atuar (PÉREZ GÓMEZ, 1992). Quanto a esse fato, assim se posicionam as docentes:

[...] temos alguns alunos com paralisia cerebral, autistas, que aprendem de forma diferente. Como trabalhar com crianças especiais? Isso me deixa insatisfeita na prática. (P1E).

Educ. Form., Fortaleza, v. 6, n. 2, e3434, maio/ago. 2021

DOI: https://doi.org/10.25053/redufor.v6i2.3434

https://revistas.uece.br/index.php/redufor/index 
[...] turma com diferenças e ritmos de aprendizado, assim a prática fica insatisfeita. (P6E).

[...] às vezes, sinto que estou impaciente com os alunos. (P2E).

[...] estou totalmente insatisfeita, preciso aprender muito. (P13E).

[...] percebo que a minha prática precisa ser mais dinâmica e criativa. Sinto falta disso, o que gera uma insatisfação no processo de alfabetizar. (P2E).

As participantes da pesquisa demonstram que estão atentas às condições apresentadas em sala de aula, seja com relação aos alunos com necessidades especiais, seja com as formas que utilizam para planejar suas aulas, evidenciando que estão insatisfeitas por não se considerarem criativas e dinâmicas. Para Martins (1996), os professores refletem sobre sua prática quando percebem que não estão atingindo seus objetivos e que sua ação pedagógica precisa atender aos interesses e às necessidades de forma concreta.

Por meio da reflexão que realizam e das interrogações de sua prática, as professoras mudam o pensar e o aprender e buscam conhecimentos para melhor ensinar. Como pontua Freire (1983, p. 27), "[...] o conhecimento, pelo contrário, exige uma presença curiosa do sujeito face ao mundo. Requer sua ação transformadora sobre a realidade. Demanda uma busca constante. Implica em invenção e em reinvenção". A reflexão crítica sobre o conhecimento de cada um faz reconhecer-se, perceber-se e conhecer as implicações que condicionam seu ato.

Em se tratando da transformação da realidade e das percepções de satisfação da prática das professoras, elas esclarecem que reformulam sua prática quando refletem sobre suas ações com os alunos, com o planejamento e com a própria necessidade. Elas relatam também sobre apresentar um mundo novo aos discentes não só pela leitura das letras e pelo conhecimento delas, mas também pelo sentido de Ihes propiciar sonhar com uma vida melhor, incentivá-los a buscar experiências e aprendizados.

Entendemos, com isso, que há uma intencionalidade em ampliar a leitura de mundo, como defende Freire (1996), por meio de reformulação da prática, quando percebem a necessidade de movimentos de mudanças:

[...] o professor precisa investigar seu aluno, procurar meios que efetivem seu aprendizado, reorganizando, assim, a prática em sala de aula. (P16Q).

Educ. Form., Fortaleza, v. 6, n. 2, e3434, maio/ago. 2021

DOI: https://doi.org/10.25053/redufor.v6i2.3434

https://revistas.uece.br/index.php/redufor/index 
[...] apresentar esse mundo novo de aprendizado não é fácil, mas, quando se tem vontade de buscar mais sobre o conteúdo trabalhado, é satisfatório para a professora. (P11Q).

[...] fico satisfeita com a prática quando vejo aquele aluno que não estava conseguindo, que está difícil, de repente aprendeu a escrever o nome. (P8E).

Reconhecemos junto às professoras alfabetizadoras iniciantes que elas realizam um percurso significativo de reflexão sobre sua prática ao constatarem que precisam reformulá-la, pois elas ficam satisfeitas com sua prática quando efetivam um trabalho reflexivo que visa ao aprendizado do educando. As profissionais pontuam ainda que:

[...] tem momentos em sala de aula que me levam ao confronto de estar fazendo certo ou não: 'Será que estou fazendo o melhor?'. Procuro trazer jogos simples, com tampas de garrafas, papel-cartão, atividades com materiais concretos para auxiliar a prática. Vejo que precisam disso. (P4E).

[...] procuro trazer desafios para os alunos, jogos, trazer atividades concretas, assim percebo que eles conseguem realizar as atividades. (P7E).

[...] o aluno passa 200 dias na escola; ele tem que aprender; ele não pode sair sem aprender nada. Eu preciso fazer algo. Preciso estimular de alguma forma. Então, eu me cobro muito e penso muito sobre o aprender dos alunos (P9E).

As professoras reconhecem a necessidade de uma reflexão fundamentada no conhecimento científico, a qual fornece elementos para enriquecer a prática docente. Nessa dimensão, percebemos que a reflexão sobre a prática possibilita à docente iniciante esclarecimentos sobre sua ação frente aos seus estudantes, destinando-se a refletir sobre como trazer para a sala de aula atividades que propiciem aos alunos refletir e aprender o conteúdo, não por meio de um único método. Para Santos (1992, p. 134), "[...] apesar das dificuldades e obstáculos colocados pela escola, não há dúvida de que o movimento prático dos trabalhadores do ensino tem avançado em direção à ampliação das relações sociais de tipo novo no interior da escola", proporcionando aos professores novas relações e reflexões sobre seu papel de agentes educacionais, realizando práticas alternativas que integrem e desenvolvam as habilidades dos discentes.

Além de pesar sobre sua prática alfabetizadora, as professoras pensam sobre a sua formação inicial e continuada. Algumas profissionais alfabetizadoras que se encontram em salas de alfabetização na RME possuem caminhos diferentes de chegada até $\mathrm{o}$ interesse pela licenciatura em Pedagogia e consequentemente pela formação como docente. 
Veiga (2008) esclarece que formar o docente é educar o futuro profissional para o exercício do magistério; é uma ação a ser desenvolvida com um sujeito que terá como tarefa ensinar, aprender, pesquisar e avaliar. A autora destaca que a formação inicial possibilita ao futuro professor adquirir conhecimentos iniciais que necessitam ser constantemente renovados. A formação inicial é, desse modo, o primeiro passo para transformar-se em profissional.

Ao tratarem da formação inicial, Brandt e Hobold (2019) destacam potencialidades da articulação entre pesquisa, teoria e prática; e Romanowski (2016) salienta que a formação frágil dos conhecimentos centrados apenas no campo das disciplinas faz pouca articulação com a prática profissional docente e com o cotidiano do espaço escolar. Essa falta de articulação dos conhecimentos curriculares das instituições superiores com o contexto da prática e da sala de aula foi identificada nos relatos das professoras alfabetizadoras iniciantes, como apontam os excertos seguintes:

[...] na minha formação inicial, houve algumas falhas, principalmente na alfabetização. (P13E).

[...] na Pedagogia, o conteúdo foi mais denso; na Pedagogia, as aulas são para formar professores para ensinar na universidade. Faltaram na universidade aulas para organizar o espaço da sala de aula, materiais, o que dificulta a docência na Educação Básica. (P7E).

[...] na universidade, os conhecimentos levam para o que fazer, para que fazer. (P9E).

As professoras revelam suas angústias e também as lacunas que fizeram parte do processo de sua formação. Mesmo diante das falhas consideradas pelas docentes, elas buscam demonstrar interesse em outras formas de conhecimentos que supram suas dúvidas e suas dificuldades. Dessa forma, evidenciam a disposição de repensar sua prática, culminando na formação continuada.

Quando questionadas sobre a participação em cursos e projetos de formação, as professoras assim se posicionam:

[...] a prefeitura sempre está oferendo curso de formação, palestras, sobre Matemática, Português. (P6E).

[...] sempre tem cursos para escolhermos. O último que fiz foi sobre as mídias no Núcleo de Tecnologia. (P8E).

Educ. Form., Fortaleza, v. 6, n. 2, e3434, maio/ago. 2021

DOI: https://doi.org/10.25053/redufor.v6i2.3434

https://revistas.uece.br/index.php/redufor/index 
[...] a prefeitura tem possibilitado aos professores fazerem muitos cursos. (P10E).

[...] vou começar o pacto. (P11E).

Durante as entrevistas, foi possível identificar que as professoras também buscam o que Vaillant e Marcelo (2012) identificam como autoformação:

[...] procuro me formar com os textos e livros de alfabetização que têm na escola. (P4E).

[...] o professor tem que buscar também. Se ele está sentindo dificuldade, precisa ir buscar, não só ficar esperando. (P10E).

[...] quero estudar mais, fazer uma pós-graduação. (P15E).

[...] sempre procuro fazer cursos. (P9E).

É um momento que, de forma individual ou em grupo, os indivíduos assumem que precisam buscar seu próprio desenvolvimento profissional, ou seja, tornam-se sujeitos da sua própria formação. "[...] trata-se de um processo que conjuga a aquisição de saberes, a construção de sentido e transformação de si mesmo desenvolve-se nas práticas sociais e na vida" (VAILLANT; MARCELO, 2012, p. 34).

A autoformação está presente no processo de novos conhecimentos profissionais do alfabetizador iniciante, trazendo para si o que Vaillant e Marcelo (2012) consideram aprendizagem do adulto, que se dá na vontade de formar-se, ocorrendo, assim, um movimento interno do professor em desejar ampliar saberes.

Sobre a contribuição da formação para a prática alfabetizadora, as professoras pesquisadas relatam que os cursos e a procura por novas formas de práticas auxiliam e provocam mudanças. Os dados seguintes evidenciam o pensamento das docentes:

[...] então, o último curso que fiz aprendi a passar o texto das crianças no retroprojetor e mostrei aos alunos o texto deles. Assim, fomos lendo o texto exposto e fazendo as correções com a turma. Foi mágico. Eles viram a letrinha deles ali. (P8E).

[...] conhecimentos valiosos que ajudam na prática. A partir do momento que eu penso no meu aluno, eu tenho que me formar, não posso ficar parada. (P9E).

[...] minha formação está caminhando junto às necessidades da minha prática. (P10E).

[...] eu comecei um curso na área de alfabetização para me ajudar na prática. (P13E).

Educ. Form., Fortaleza, v. 6, n. 2, e3434, maio/ago. 2021

DOI: https://doi.org/10.25053/redufor.v6i2.3434

https://revistas.uece.br/index.php/redufor/index 
[...] a formação contribui, possibilita novas ideias para você produzir com seus alunos; tira um pouco da angústia da prática. (P14E).

As professoras destacam a importância da formação e como ela contribui diretamente para a prática alfabetizadora. Sobre esse processo de formação, salientamos que ela só tem sentido quando os indivíduos são agentes de sua formação ao decidirem ampliar os seus conhecimentos, seja por meio de formação ofertada pelo campo de trabalho, seja por meio do próprio interesse por novos desafios que constituirão sua prática. "[...] por isso é que na formação permanente dos professores, o momento fundamental é o da reflexão crítica sobre a prática" (FREIRE, 2001, p. 43).

\section{Considerações finais: sobre o processo de produção da prática pedagógica e as contribuições para a formação das alfabetizadoras}

Para compreender como ocorre o processo de produção das práticas pedagógicas de professoras alfabetizadoras, consideramos o contexto histórico em que são produzidas e apoiamo-nos em uma teoria em que todos são produtores e distribuem conhecimentos, por meio das suas experiências e pelo movimento da prática que realizam com a intenção de resolver problemas e conflitos. Esse é o ponto de partida para pensar o processo formativo das professoras alfabetizadoras iniciantes.

Os estudos indicam que os docentes iniciantes sofrem com o choque de realidade e passam por um período em que vão se constituindo e construindo. Para o alfabetizador iniciante, um elemento a mais destaca-se: o desafio de trabalhar com a especificidade da alfabetização, que requer conhecimentos específicos sobre a língua materna e as metodologias que orientam o processo de aquisição da leitura e escrita.

As estratégias para passar por esse período de inserção profissional concentram-se principalmente na busca pelos pares, que podem oferecer apoio tanto nas questões pessoais como nas pedagógicas. No entanto, os determinantes externos, como as avaliações e as demandas burocráticas, têm ocupado o tempo dos professores, diminuindo os espaços de trabalho mais coletivos. Nesse contexto, apesar de todos os desafios postos pela prática, as professoras demonstraram ter autoria no processo de pensar a sua prática associada ao compromisso de aprendizagem do estudante. Esse

Educ. Form., Fortaleza, v. 6, n. 2, e3434, maio/ago. 2021 
aspecto reforça nossa defesa epistemológica sobre o sujeito histórico e produtor de conhecimento.

Nesse sentido, Martins (1996) destaca que o movimento de pensar criticamente constrói novas formas de organização social e da relação com o conhecimento, pois a base do conhecimento passa a ser a ação prática que os sujeitos realizam de forma crítica, refletindo e organizando sua visão de mundo. Assim, as formas e as práticas de interação dos professores, dos alunos e dos conhecimentos emergem dos conflitos práticos e não se reduzem à causa e ao efeito de conteúdo determinado.

Diante disso, retomamos, com Martins (1996), que o processo de produção da prática docente é momento de produção de conhecimento, ou seja, a teoria é a expressão da sua ação prática. As formas de alfabetização necessitam, portanto, de reflexões, visto que os sujeitos não aprendem em uma linearidade, mas sim em formas e perspectivas diferentes. Assim, após as análises construídas neste texto, elegemos dois pontos principais que podem contribuir no processo formativo do professor alfabetizador iniciante: espaços coletivos de trabalho e formação em conhecimentos específicos para a alfabetização.

A ampliação dos espaços coletivos de trabalho decorre da necessidade de estabelecer parcerias incentivadoras da constituição da docência nos espaços colaborativos (BRANDT; HOBOLD, 2019), a fim de garantir espaços de trocas com os pares e discussões sobre os desafios específicos dos iniciantes. Esses espaços coletivos podem assumir uma perspectiva dialógica (SOARES, 2019) como forma de resistência ao viés produtivista que recai sobre a escola e o trabalho dos professores, levando-os, muitas vezes, a um trabalho mais individualista e competitivo. Contudo, Santos (1992) explica que os trabalhadores realizam movimentos que resultam em um processo de luta pela igualdade, gerando, assim, formas coletivas de se organizar para fomentar relações anticapitalistas, as relações de tipo novo. Estas aparecem, mesmo que de forma embrionária, no processo de produção da prática das professoras alfabetizadoras iniciantes.

A formação em conhecimentos específicos para a alfabetização é uma forma de contemplar os elementos necessários para compreender as disputas metodológicas polêmicas que circundam o campo da alfabetização, o que, para Soares (2004), compreende mais questões políticas do que propriamente conceituais. Soares (2004, 
2016) alerta sobre a necessidade da "reinvenção da alfabetização", olhar para a especificidade do ensino em uma perspectiva de alfabetizar letrando.

Conhecer e discutir a alfabetização a partir da contribuição das ciências é fundamental para que 0 alfabetizador possa compreender os desafios da prática de forma contextualizada e tomar decisões fundamentadas sobre as metodologias de ensino. São reflexões propositivas que buscam dialogar com as universidades, Secretarias de Educação e equipes pedagógicas das escolas sobre as professoras alfabetizadoras iniciantes, seus desafios e o contexto de suas práticas.

\section{Referências}

BARDIN, L. Análise de conteúdo. 2. ed. São Paulo: 70, 2011.

BRANDT, A.; HOBOLD, M. A prática como componente curricular na disciplina pesquisa e processos educativos do curso de pedagogia: um diferencial na relação entre pesquisa, teoria e prática. Educação \& Formação, Fortaleza, v. 4, n. 2, p. 142-160, 2019. DOI: https://doi.org/10.25053/redufor.v4i11.319. Disponível em: https://revistas.uece.br/index.php/redufor/article/view/319. Acesso em: 20 jun. 2020.

CARTAXO, S. R. M.; FONTANA, M. I.; SMAIOTTO, G. C. As facetas da alfabetização nos cursos de Pedagogia: desafios para a formação do professor. Currículo sem fronteras, [S.I.], v. 20, n. 3, p. 1126-1147, 2020. DOI: http://dx.doi.org/10.35786/16451384.v20.n3.25. Disponível em:

http://www.curriculosemfronteiras.org/vol20iss3articles/cartaxo-smaniotto-fontana.html. Acesso em: 20 jun. 2020.

CARTAXO, S. R. M.; ROMANOWSKI, J. P.; MARTINS, P. L. Tensões e prioridades no processo de formação continuada do alfabetizador: da concepção à prática de formação. Práxis Educativa, Ponta Grossa, v. 11, n. 3, p. 861-880, 2016. DOI: https://doi.org/10.5212/PraxEduc.v.11i3.0020. Disponível em: https://dialnet.unirioja.es/servlet/articulo?codigo=5577324. Acesso em: 20 jun. 2020.

FONSECA, M. G. R. As tecnologias de informação e comunicação na formação inicial de professores do $1^{\circ}$ ciclo do ensino básico - fatores constrangedores invocados pelos formadores para o uso das tecnologias. Educação \& Formação, Fortaleza, v. 4, n. 2, p. 3-23, 2019. DOI: https://doi.org/10.25053/redufor.v4i11.254. Disponível em: https://revistas.uece.br/index.php/redufor/article/view/254. Acesso em: 20 jun. 2020.

FRADE, I. C. A. S. Um paradigma científico e evidências a ele relacionadas resolveriam os problemas da alfabetização brasileira?. Revista Brasileira de Alfabetização, Belo Horizonte, v. 1, n. 10, p. 15-25, 2019. Disponível em: 
http://abalf.org.br/revistaeletronica/index.php/rabalf/article/view/339. Acesso em: 10 maio 2020.

FREIRE, P. Conscientização. São Paulo: Cortez, 1983.

FREIRE, P. Pedagogia da autonomia: saberes necessários à prática. Rio de Janeiro: Paz e Terra, 1996.

FREIRE, P. Política e educação: ensaios. 5. ed. São Paulo: Cortez, 2001.

HOÇA, L.; ROMANOWSKI, J. P.; CARTAXO, S. R. M. Professores alfabetizadores: estudo sobre elementos do desenvolvimento profissional. Revista Diálogo Educacional, Curitiba, v. 16, n. 50, p. 937-965, 2016. DOI: http://dx.doi.org/10.7213/1981416x.16.050.ds07. Disponível em:

https://periodicos.pucpr.br/index.php/dialogoeducacional/article/view/2896. Acesso em: 10 jun. 2020.

HUBERMAN, M. O ciclo de vida profissional dos professores. In: NÓVOA, A. (coord.). Vidas de professores. Porto: Porto, 1995. p. 31-78.

MARTINS, P. L. O. A relação conteúdo-forma: expressão das contradições da prática pedagógica na escola capitalista. In: VEIGA, I. P. A. (org.). Didática: o ensino e suas relações. Campinas: Papirus, 1996. p. 77-103.

MIRA, M. M. et al. Processos de inserção profissional de professores iniciantes na Rede Municipal de Ensino de Curitiba. In: CONGRESSO INTERNACIONAL SOBRE PROFESSORADO PRINCIPIANTE E INSERÇÃO PROFISSIONAL À DOCÊNCIA, 4., 2014, Curitiba. Anais [...]. Curitiba: UTFPR, 2014. [CD-ROM].

MIRA, M. M.; ROMANOWSKI, J. P. Processos de inserção profissional docente nas políticas de formação: o que documentos legais revelam. Acta Scientiarum: Education, Maringá, v. 38, n. 3, p. 283-292, 2016. DOI:

https://doi.org/10.4025/actascieduc.v38i3.27641. Disponível em:

http://periodicos.uem.br/ojs/index.php/ActaSciEduc/article/view/27641. Acesso em: 10 jun. 2020.

MORTATTI, M. R. L. A "Política nacional de alfabetização" (Brasil, 2019): uma "guinada" (ideo)metodológica para trás e pela direita. Revista Brasileira de Alfabetização, Belo Horizonte, v. 1, n. 10, p. 15-25, 2019. DOI: https://doi.org/10.47249/rba.2019.v1.348. Disponível em: https://revistaabalf.com.br/index.html/index.php/rabalf/article/view/348. Acesso em: 10 jun. 2020.

MORTATTI, M. R. L. História dos métodos de alfabetização no Brasil. 2006. Disponível em: http://portal.mec.gov.br/seb/arquivos/pdf/Ensfund/alf mortattihisttextalfbbr.pdf. Acesso em: 20 nov. 2017. 
PÉREZ GÓMEZ, A. O pensamento prático reflexivo do professor como profissional reflexivo. In: NÓVOA, A. (org.). Os professores e a sua formação. 2. ed. Lisboa: Dom Quixote, 1992. p. 93-114.

ROMANOWSKI, J. P. Conhecimentos pedagógicos nos cursos de licenciatura e a base comum de formação de professores. In: ROMANOWSKI, J. P. et al. (org.). Práticas de formação de professores da Educação básica à Educação Superior. Curitiba: PUCPR, 2016. p. 47-69.

SANTOS, O. J. Pedagogia dos conflitos sociais. Campinas: Papirus, 1992.

SOARES, M. Alfabetização: a questão dos métodos. São Paulo: Contexto, 2016.

SOARES, M. Letramento e alfabetização: as muitas facetas. Revista Brasileira de Educação, Rio de Janeiro, n. 25, p. 5-17, 2004. Disponível em: http://www.scielo.br/pdf/rbedu/n25/n25a01.pdf. Acesso em: 20 out. 2020.

SOARES, M. B. Formação permanente de professores: um estudo inspirado em Paulo Freire com docentes dos anos iniciais do ensino fundamental. Educação \& Formação, Fortaleza, v. 5, n. 1, p. 151-171, 2019. DOI: https://doi.org/10.25053/redufor.v5i13.1271. Disponível em: https://revistas.uece.br/index.php/redufor/article/view/1271. Acesso em: 10 jun. 2020.

VAILLANT, D.; MARCELO, C. Ensinando a ensinar: as quatro etapas de uma aprendizagem. Curitiba: UTFPR, 2012.

VEIGA, I. P. A. Organização didática da aula: um projeto colaborativo de ação imediatista. In: VEIGA, I. P. A. (org.). Aula: gênese, dimensões, princípios e práticas. 2. ed. Campinas: Papirus, 2011. p. 267-298.

VEIGA, I. P. A. Profissão docente: novos sentidos, novas perspectivas. São Paulo: Papirus, 2008.

\footnotetext{
Simone Regina Manosso Cartaxo, Universidade Estadual de Ponta Grossa, Departamento de Pedagogia i-Dhttps://orcid.org/0000-0002-8670-6324

Doutora em Educação pela Pontifícia Universidade Católica do Paraná. Professora do Departamento de Pedagogia e do Programa de Pós-Graduação em Educação da Universidade Estadual de Ponta Grossa. Coordena o Grupo de Estudos e Pesquisas - Didática e Formação Docente (Gepedido) e integra a Rede Interinstitucional de Pesquisas sobre a Formação e as Práticas Docentes (Ripefor).

Contribuição de autoria: Planejamento e orientação da pesquisa e organização do texto.

Lattes: http://lattes.cnpq.br/9326211816965126

E-mail: simonemcartaxo@hotmail.com
} 
Josemary Scos, Universidade Estadual de Ponta Grossa, Rede Municipal de Ensino de Ponta Grossa

ii Dhttps://orcid.org/0000-0002-8987-274X

Mestra em Educação pela Universidade Estadual de Ponta Grossa. Professora da Rede Municipal de Ensino de Ponta Grossa. Integra o Grupo de Estudos e Pesquisas - Didática e Formação Docente (Gepedido) e a Rede Interinstitucional de Pesquisas sobre a Formação e as Práticas Docentes (Ripefor).

Contribuição de autoria: Planejamento da pesquisa, coleta e análise dos dados e organização do texto.

Lattes: http://lattes.cnpq.br/8466176101300757

E-mail: josyscos@hotmail.com

Editora responsável: Lia Machado Fiuza Fialho Pareceristas ad hoc: Maria Lília Colares e Isabel Farias

\section{Como citar este artigo (ABNT):}

CARTAXO, Simone Regina Manosso; SCOS, Josemary. Prática pedagógica de professoras alfabetizadoras iniciantes: processos de produção e contribuições para a formação. Educ. Form., Fortaleza, v. 6, n. 2, e3434, 2021. Disponível em: https://revistas.uece.br/index.php/redufor/article/view/3434

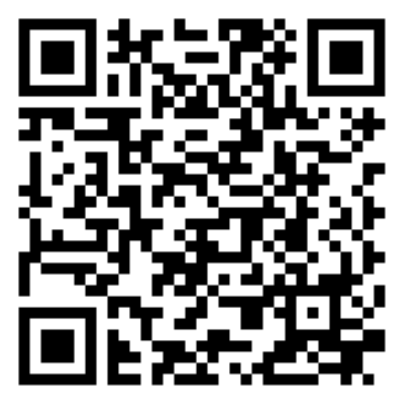

Recebido em 26 de ago de 2020.

Aceito em 9 de novembro de 2020.

Publicado em 24 de fevereiro de 2021. 